\title{
Bilateral Tripartite Insertion of the Fibularis (Peroneus) Brevis Muscle: a Case Report
}

\author{
Inserción Tripartita Bilateral del Músculo Fibular Corto: Reporte de Caso
}

\author{
Benjamin W. C. Rosser; Ashraf H. Salem; Saheed A. Gbamgbola \& Adel Mohamed
}

\begin{abstract}
ROSSER, B. W. C.; SALEM, A. H.; GBAMGBOLA, S. A. \& MOHAMED, A. Bilateral tripartite insertion of the fibularis (peroneus) brevis muscle: A case report. Int. J. Morphol., 37(2):481-485, 2019.

SUMMARY: The fibularis brevis muscle typically inserts by a single long, robust, flat tendon upon the base of the fifth metatarsal. In this case report, we demonstrate two comparatively small accessory tendons of insertion in both the right and left limbs of an elderly cadaver. In each limb, the superior and inferior accessory tendons arose from the distal end of the main tendon of insertion to attach to, respectively, the shaft and neck of the fifth metatarsal. The bilateral presence of this comparatively rare condition is a new finding. Review of the literature reveals that these accessory tendons are most probably remnants of the inserting tendons of the atavistic muscle peroneus digiti minimi. The presence of this anomaly could affect reconstruction surgeries that utilize the inserting tendon of fibularis brevis, and treatment of avulsion fractures of the base of the fifth metatarsal.
\end{abstract}

KEY WORDS: Fibularis brevis muscle; Peroneus brevis muscle; Insertion; Tendon; Anomaly.

\section{INTRODUCTION}

As muscles of the lateral (fibular or peroneal) compartment of the leg are essential in the management of ankle pathologies and important tools in surgical reconstruction, comprehension of the anatomic variants of these muscles is crucial (Davda et al., 2017). The lateral compartment is supplied by the superficial fibular nerve and normally contains just two muscles, fibularis brevis and fibularis longus. These muscles are also commonly referred to, respectively, as peroneus brevis and peroneus longus. In this work we follow Standring (2016) in using fibularis instead of peroneus. Exceptions to this are accessory muscles, termed peroneus in the literature, that are not included in Terminologia Anatomica.

The fusiform-shaped belly of the fibularis brevis muscle is situated deep to the larger fibularis longus muscle (Standring). Fibularis brevis muscle originates from the distal two-thirds of the lateral surface of the shaft of the fibula, anterior and distal to the origin of fibularis longus muscle, which arises from the head and proximal lateral two-thirds of the fibula. Both muscles arise from the adjacent anterior and posterior intermuscular septa. Fibularis brevis muscle passes vertically down the leg and two to four centimeters proximal to the distal end of the fibula it tapers into a long flat tendon. This tendon descends posterior to the lateral malleolus of the fibula, anterior to the juxtaposed and more rounded inserting tendon of fibularis longus. Both of these lengthy tendons then turn anteriorly to cross the lateral surface of the calcaneus, where the tendon of fibularis brevis is the more dorsal of the two. The tendon of fibularis longus muscle then makes an approximately ninety-degree turn medially, deep to the calcaneus, to cross beneath the sole of the foot to insert upon the plantar surfaces of the medial cuneiform and first metatarsal. The tendon of fibularis brevis muscle continues distally to insert onto a tuberosity on the lateral aspect of the base of the fifth metatarsal (Fig. 1) (Standring). The main actions of these two fibular muscles are to evert and plantarflex the foot, maintain the concavity of the foot, and stabilize talocrural and subtalar joints (Ziai et al., 2013; Standring).

\section{CASE PRESENTATION}

The Body Bequeathal Program at the University of Saskatchewan requires that written informed consent be obtained from each donor confirming and approving the use of their body tissues after death for educational and research purposes. 


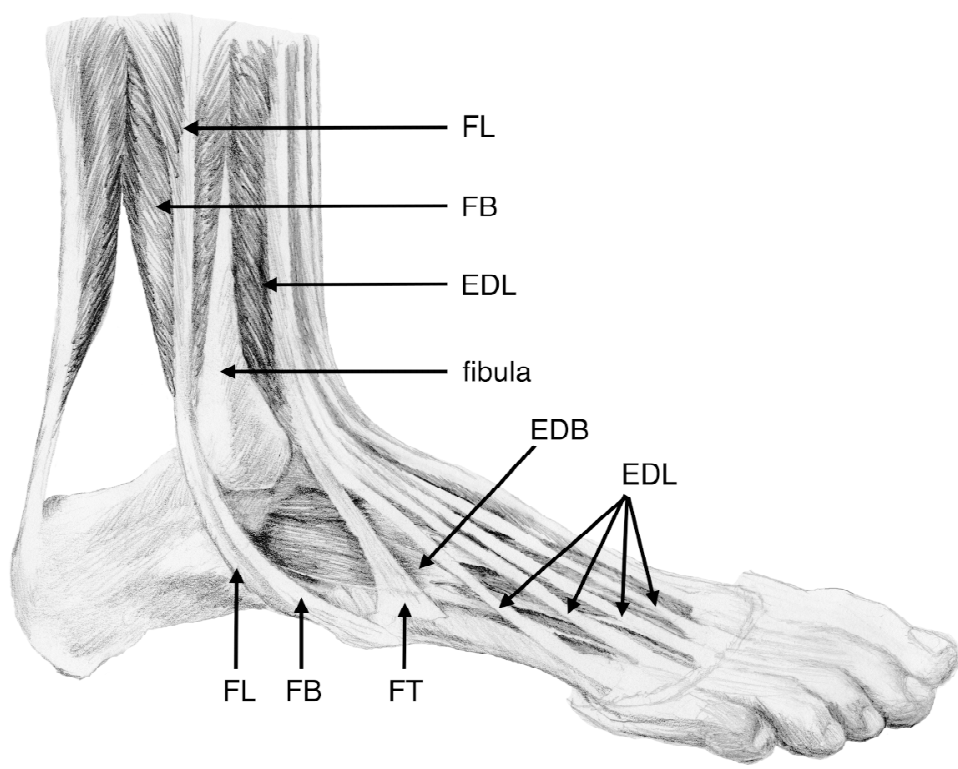

Fig. 1. Drawing of dissection of right foot, lateral view. Abbreviations: EDB Extensor digitorum brevis muscle, EDL Extensor digitorum longus muscle, FB Fibularis brevis muscle, FL Fibularis longus muscle, FT Fibularis tertius muscle. The base of the fifth metatarsal receives the normal, single, insertion of FB.

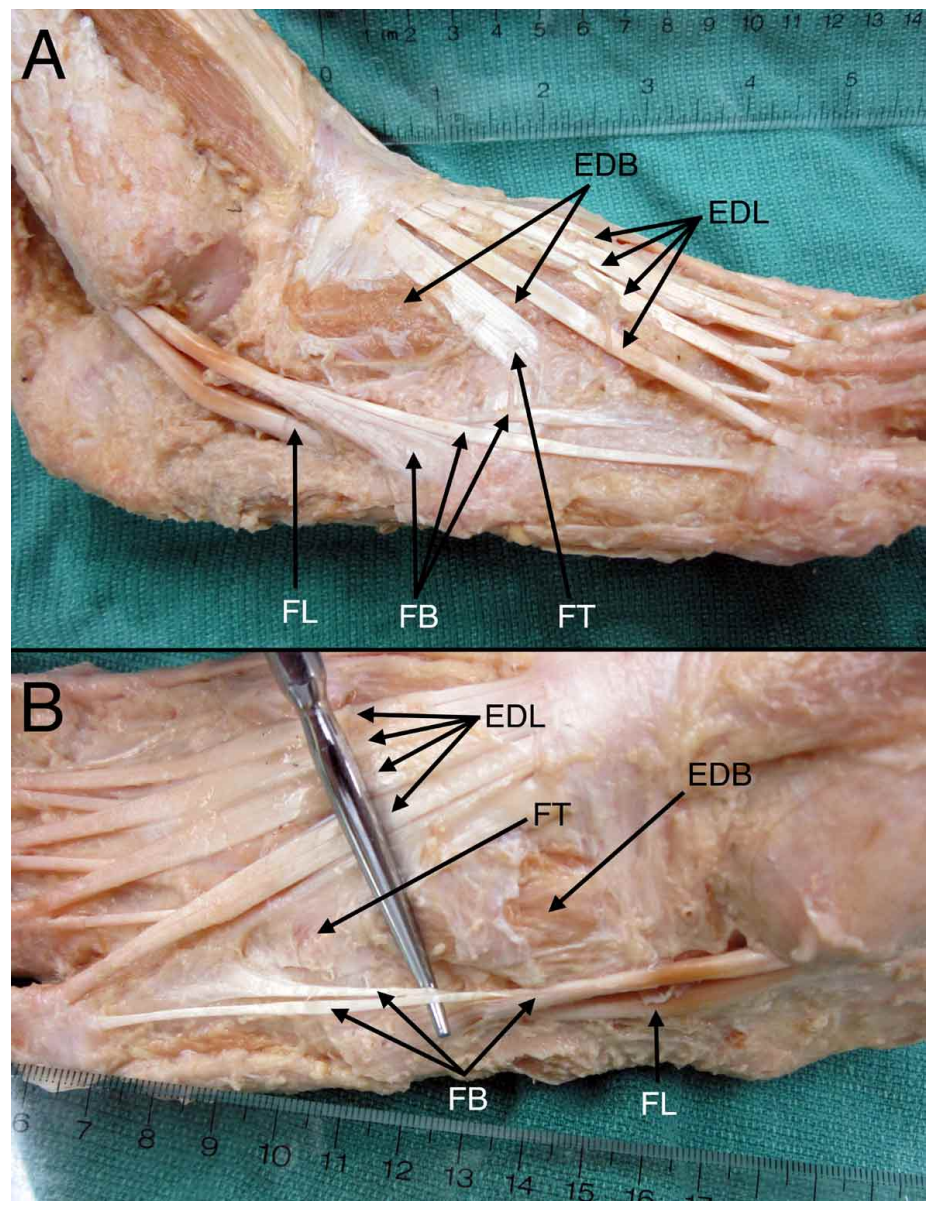

Routine dissection and study of a 74-year old Caucasian female cadaver by medical and physical therapy students in our Department revealed an anomaly in the insertion of the fibularis brevis muscle of the right leg. Further dissection by teaching staff (AHS \& SAG) showed the extent of this anomaly, and confirmed the same condition within the contralateral limb. The limbs showed no atrophy, signs of trauma, deformity, surgical scars nor indication of prior surgical intervention.

Dissection demonstrated, in agreement with the usual description in the literature, that the belly of the fibularis brevis muscle originated on the lateral surface of the lower two-thirds of the fibula and its long flat tendon of insertion attached to the base of fifth metatarsal. The innervation was the usual for the fibularis brevis muscle, the superficial fibular nerve. However, in each limb there were an additional two small thin accessory inserting tendons, one inferior and the other superior. Each of these tiny thin slips arose from the dorsal surface of distal end of the much larger main tendon, just prior to its insertion (Fig. 2). The inferior accessory tendon passed distally to attach to the lateral aspect of the neck of fifth metatarsal bone. The superior accessory tendon, thicker and shorter by comparison, also passed distally and inserted into fascia and connective tissues over the dorsal aspect of the shaft of the fifth metatarsal bone. Consequently, the fibularis brevis muscle had a tripartite insertion in both the right and left limbs of the donor.

\section{DISCUSSION}

Anatomic variants of human muscles are commonly encountered. These may consist of the absence of a muscle, supernumerary (duplicate) muscles, accessory (additional) muscles or an anomalous origin or insertion (Sookur et al., 2008). The fibular muscles are highly variable (Lucas et $a l ., 2013)$. This variance is believed to be related the acquisition of bipedalism by ancestral humans (Johnson, 1973; Yammine, 2015).

Fig. 2. Photograph of Dissection of the Right Foot (A) and the Left Foot (B). Abbreviations: EDB Extensor digitorum brevis muscle, EDL Extensor digitorum longus muscle, FB Fibularis brevis muscle, FL Fibularis longus muscle, FT Fibularis tertius muscle. Ruler features centimeters and inches. In each foot, a tripartite insertion of FB is shown. 
Fibularis tertius muscle, unlike the other fibular muscles, is supplied by the deep fibular nerve and is in the anterior (extensor) compartment of the leg. It arises from the distal third of the medial surface of the fibula, the adjacent anterior interosseous membrane and the anterior intermuscular septum. The tendinous insertion is onto the medial part of the dorsal surface of the base of the fifth metatarsal. It is both a dorsiflexor and evertor of the foot (Standring). Fibularis tertius muscle is inconstant in size and shape, and is absent in five to $20 \%$ of limbs (Albay \& Candan, 2017).

There are recognized variants of the muscles within the lateral compartment of the leg (Standring). Approximations of the incidence of accessory fibular muscles have ranged widely from one to $29 \%$ of limbs. Yammine estimated $16 \%$ of limbs and Hur et al. (2015) $16.3 \%$. The presence of accessory fibular muscles may result in ankle pain, ankle instability and/or stenosis in the lateral compartment. These pathologies can cause degeneration or tendon tear of fibularis brevis muscle (Clarkson et al., 2013). There may also be supernumerary fibularis brevis and fibularis longus muscles (Mehta et al., 2011). Pes planus (flat foot) and talipes equinovarus (club foot) have both been associated with abnormalities of the fibular tendons (Johnson).

Fibularis longus muscle typically exhibits much variation in its insertion (Patil et al., 2007). While the usual attachment is by a strong band to the base of the first metatarsal, there is usually an additional slip to the medial cuneiform. In a case report (Jayakumari et al. 2006), the muscle was shown to have an accessory tendon and tripartite insertion. The accessory tendon attached to the base of the first metatarsal, and a tendinous slip inserted into the neighboring dorsal interosseous muscle. Tendinous slips may also extend to the base of the third, fourth or fifth metatarsals, or the adductor hallucis muscle (Standring).

Fibularis brevis muscle has a variety of anomalous insertions. For example, instead of the normal insertion onto the lateral surface of the base of the fifth metatarsal, in about $1 \%$ of limbs the muscle attaches to the fibular tubercle of the calcaneus (Cecava \& Campbell, 2015). Another study showed the main tendon splitting into two, with separate attachments to lateral and medial sides of the base of the fifth metatarsal (Verma et al., 2011). It must also be appreciated that the usual insertion on the fifth metatarsal may vary greatly in size and shape (Seyidova et al., 2018).

Fibularis quartus muscle, an accessory muscle, is estimated to be present in $7 \%$ to $22 \%$ of limbs (reviewed by Davda et al.). It usually arises from fibularis brevis muscle, and/or a variety of other structures including fibularis longus, fibularis tertius or the fibula. While fibularis quartus muscle ordinarily inserts onto the calcaneus, there can be a number of other attachments including the cuboid, inferior peroneal retinaculum and fifth metatarsal (Clarkson et al.; Albay \& Candan). Variations in origin(s) and insertion(s) of this muscle have resulted in an assortment of names, including peroneus accessories muscle, peroneocalcaneus externum muscle, peroneocuboideus muscle, peroneocalcaneocuboideus muscle, peroneus digiti minimi muscle and others (Sookur et al.; Clarkson et al.; Albay \& Candan). Multiple synonyms and variable descriptions often exist for the same accessory fibular muscle (Yammine; Albay \& Candan). While most authors consider all of these as variants or subtypes of fibularis quartus muscle (Sobel et al., 1990; Sookur et al.; Hur et al.), others deem peroneus accessorius to be distinct (Clarkson et al.; Standring). Peroneus accessorius muscle has an origin comparable to fibularis quartus muscle, but its inserting tendon joins that of fibularis longus muscle in the sole (Standring). Still other researchers see value in recognizing an array of accessory muscles (Lucas et al.).

Peroneus digiti minimi (quinti) muscle was thoroughly reviewed by Johnson. It is currently thought by most to be a variant or subtype of fibularis quadratus muscle (reviewed by Yammine). Peroneus digiti minimi muscle, while common as a separate muscle in gorillas, chimpanzees, monkeys and six other mammalian orders, is rarely (in less than $0.8 \%$ ) present in humans. The muscle is atavistic in humans. Its miniature belly usually arises from the fibula or belly of fibularis brevis muscle, and gives rise to a tendon which passes behind the ankle before inserting upon the dorsal surface of the fifth metatarsal. Sobel et al. showed that the inserting tendon of one peroneus digiti minimi muscle split into two tendinous slips that attached separately onto the dorsum of the base and the head of the fifth metatarsal. In humans the most common manifestation of peroneus digiti minimi muscle is not as an independent muscle, but as a tendon reduction arising from the distal end of the inserting tendon of fibularis brevis muscle. In the literature, many authors do not differentiate between the presence of the entire muscle and the persistence of its tendon of insertion. Thus, the frequency of occurrence of peroneus digiti minimi muscle is confounded. A single small tendon passing from the inserting tendon of fibularis brevis muscle into the fifth metatarsal, or its associated digit, occurred in approximately $30 \%$ to $37 \%$ of limbs (Johnson). It is widely accepted that this small accessory tendon of insertion of fibularis brevis muscle is actually a tendon reduction, or remnant, of peroneus digiti minimi muscle (Johnson; Demir et al., 2015). 
Peroneus digiti minimi (quinti) tendon reductions were sought by Demir et al. in 25 lower limbs. Seventeen $(68 \%)$ limbs had the usual insertion of fibularis brevis muscle upon the base of the fifth metatarsal, but lacked any accessory tendon(s). Five (20\%) limbs had an additional single accessory slip extending from the inserting tendon of fibularis brevis muscle. Three (12 $\%$ ) limbs had two additional fine slips extending distally. The authors indicated that they were the first to describe a peroneus digiti minimi tendon reduction of two accessory slips. They felt that the tendinous remnants of peroneus digiti minimi muscle could contribute to extension of the fifth toe. Imre et al. (2016) studied the insertion of fibularis brevis muscle in 42 lower limbs. They found that it inserted as usual in $25(59.5 \%)$ limbs, had one extra inserting slip in $12(28.6 \%)$ limbs and two extra slips in five $(11.9 \%)$ limbs.

We believe that our study is the first to describe the bilateral presence of a peroneus digiti minimi tendon reduction of two fine accessory slips from the main tendon of insertion of fibularis brevis. Johnson reported that single accessory slips of insertion were usually present bilaterally. Anatomic anomalies, including muscle anomalies, occur due to genetic and/or environmental (developmental) causes (Sanudo et al., 2003). Muscular anomalies are frequently bilateral (Sookur et al.). Bilateralism of anomalies has been considered as evidence for a genetic mechanism (Peck et al., 1994; Morton et al., 2010).

We further demonstrate that the points of attachment of these two accessory slips can vary. Demir et al. described variations: for example, one long superior slip extended to the fourth metatarsal. Imre et al. illustrated two distinct variants in the superior slip: one shorter and broader inserting more proximally on the fifth metatarsal, and the other longer and thinner inserting more distally. The inferior slips depicted by Imre et al. insert more distally than those that we observed.

Accessory fibular muscles and variants of fibular muscles ought be of importance to anatomists, radiologists, podiatrists, physical therapists, sports medicine practitioners and surgeons (Yammine). Variations of the insertion of fibularis brevis muscle are particular relevant, as avulsion fractures of the base of the fifth metatarsal caused by this tendon during rapid unavoidable inversion of the foot are frequently encountered in orthopedic practice (Theodorou et al., 2003; Imre et al.). Precise anatomical knowledge of fibularis brevis tendon anatomy is an asset in determining treatment options for proximal fifth metatarsal fractures (Seyidova et al.).
Additionally, portions of the inserting tendon of fibularis brevis muscle are routinely harvested to repair damaged ankles (Monson et al., 2014). Long-term results from these surgical procedures have been mixed, as the functions of fibularis brevis muscle can be impaired (Noailles et al., 2018). Thus, prior to surgery, variations in fibularis brevis tendon morphology need be appreciated.

\section{ACKNOWLEDGEMENTS}

We are indebted to those who chose to selflessly bequeath their bodies to medical education and research at the University of Saskatchewan. The Authors thank these donors, and their families. Professor Allyson Glenn, of the Department of Art and Art History, University of Saskatchewan, expertly created the drawn illustration. Kristen Schroeder, formerly of our Department, kindly assembled photographic images into labeled plates for publication. Corrie Willfong and David Shewchuk, also of our Department, were skillful and professional in maintaining and providing access to cadaveric specimens. We also wish to thank the ever keen medical and physical therapy students at the University of Saskatchewan, whose enthusiasm and queries inspired this investigation.

ROSSER, B. W. C.; SALEM, A. H.; GBAMGBOLA, S. A. \& MOHAMED, A. Inserción tripartita bilateral del músculo fibular corto: reporte de caso. Int. J. Morphol. 37(2) 481485, 2019.

RESUMEN: El músculo fibularis corto generalmente se inserta por un solo tendón largo, robusto y plano en la base del quinto metatarsiano. En este trabajo demostramos dos tendones accesorios de inserción comparativamente pequeños en ambos miembros inferiores de un cadáver de edad avanzada. En cada miembro inferior, los tendones accesorios superiores e inferiores surgieron de la porción distal del tendón principal de inserción para adherirse, respectivamente, al eje y al cuello del quinto metatarsiano. La presencia bilateral de éste músculo, comparativamente raro, es un nuevo hallazgo. La revisión de la literatura revela que estos tendones accesorios son probablemente remanentes de los tendones de inserción del músculo peroneus digiti minimi. La presencia de esta anomalía podría afectar las cirugías de reconstrucción que utilizan el tendón de inserción del músculo fibular corto, y el tratamiento de las fracturas por avulsión de la base del quinto hueso metatarsiano.

PALABRAS CLAVE: Músculo fibular corto; Inserción; Tendón; Anomalía. 


\section{REFERENCES}

Albay, S. \& Candan, B. Evaluation of fibular muscles and prevalence of accessory fibular muscles on fetal cadavers. Surg. Radiol. Anat., 39(12):1337-41, 2017.

Cecava, N. D. \& Campbell, S. E. Peroneus brevis tendon variant insertion on the calcaneus. J. Radiol. Case Rep., 9(5):22-9, 2015.

Clarkson, M. J.; Fox, J. N.; Atsas, S.; Daney, B. T.; Dodson, S. C. \& Lambert, H. W. Clinical implications of novel variants of the fibularis (peroneus) quartus muscle inserting onto the cuboid bone: peroneocuboideus and peroneocalcaneocuboideus. J. Foot Ankle Surg., 52(1):118-21, 2013.

Davda, K.; Malhotra, K.; O'Donnell, P.; Singh, D. \& Cullen, N. Peroneal tendon disorders. EFORT Open Rev., 2(6):281-92, 2017.

Demir, B. T.; Gümüsalan, Y.; Üzel, M. \& Çevik, H. B. The variations of peroneus digiti quinti muscle and its contribution to the extension of the fifth toe. Saudi Med. J., 36(11):1285-9, 2015.

Hur, M. S.; Won, H. S. \& Chung, I. H. A new morphological classification for the fibularis quartus muscle. Surg. Radiol. Anat., 37(1):27-32, 2015.

Imre, N.; Kocabiyik, N.; Sanal, H. T.; Uysal, M.; Ozan, H. \& Yazar, F. The peroneus brevis tendon at its insertion site on fifth metatarsal bone. Foot Ankle Surg., 22(1):41-5, 2016.

Jayakumari, S.; Suri, R. K.; Rath, G. \& Arora, J. Accessory tendon and tripartite insertion pattern of fibularis longus muscle: a case report. Int. J. Morphol., 24(4):633-6, 2006.

Johnson, D. C. Tendon Variations of the Peroneal Musculature in Man. New Haven, Yale Medicine Thesis Digital Library, 1973. Available from: https:/ /elischolar.library.yale.edu/ymtdl/2

Lucas, D. E.; Hyer, C. F.; Berlet, G. C. \& Shockley, J. A. Anomalous peroneal tendon insertion masquerading as a retracted tendon tear: case report. Foot Ankle Int., 34(4):603-6, 2013.

Mehta, V.; Suri, R. K.; Arora, J.; Dave, V. \& Rath, G. Supernumerary peronei in the leg musculature- utility for reconstruction. Chang Gung Med. J., 34(6 Suppl.):62-5, 2011.

Monson, D. K.; Vojdani, S.; Dean, T. J. \& Louis-Ugbo, J. Lateral ankle stabilization after distal fibular resection using a novel approach: a surgical technique. Clin. Orthop. Relat. Res., 472(4):1262-70, 2014.

Morton, R. P.; Ahmad, Z. \& Jain, P. Plunging ranula: congenital or acquired? Otolaryngol. Head Neck Surg., 142(1):104-7, 2010.

Noailles, T.; Lopes, R.; Padiolleau, G.; Gouin, F. \& Brilhault, J. Nonanatomical or direct anatomical repair of chronic lateral instability of the ankle: A systematic review of the literature after at least 10 years of followup. Foot Ankle Surg., 24(2):80-5, 2018.

Patil, V.; Frisch, N. C. \& Ebraheim, N. A. Anatomical variations in the insertion of the peroneus (fibularis) longus tendon. Foot Ankle Int., 28(11):117982, 2007.

Peck, S.; Peck, L. \& Kataja, M. The palatally displaced canine as a dental anomaly of genetic origin. Angle Orthod., 64(4):249-56, 1994.

Sanudo, J. R.; Vazquez, R. \& Puerta, J. Meaning and clinical interest of the anatomical variations in the $21^{\text {st }}$ century. Eur. J. Anat., 7 (Suppl. 1):1-3, 2003.

Seyidova, N.; Hirtler, L.; Windhager, R.; Schuh, R. \& Willegger, M. Peroneus brevis tendon in proximal 5th metatarsal fractures: Anatomical considerations for safe hook plate placement. Injury, 49(3):720-5, 2018.

Sobel, M.; Levy, M. E. \& Bohne, W. H. Congenital variations of the peroneus quartus muscle: an anatomic study. Foot Ankle, 11(2):81-9, 1990.

Sookur, P. A.; Naraghi, A. M.; Bleakney, R. R.; Jalan, R.; Chan, O. \& White, L. M. Accessory muscles: anatomy, symptoms, and radiologic evaluation. Radiographics, 28(2):481-99, 2008.

Standring, S. Gray's Anatomy. The Anatomical Basis of Clinical Practice. 41 st ed. New York, Elsevier, 2016.

Theodorou, D. J.; Theodorou, S. J.; Kakitsubata, Y.; Botte, M. J. \& Resnick, D. Fractures of proximal portion of fifth metatarsal bone: anatomic and imaging evidence of a pathogenesis of avulsion of the plantar aponeurosis and the short peroneal muscle tendon. Radiology, 226(3):857-65, 2003.
Verma, P.; Arora, A. K. \& Abrol, S. Bifurcation of tendon of peroneus brevis in human cadavers: case study. J. Life Sci., 3(1):13-5, 2011.

Yammine, K. The accessory peroneal (fibular) muscles: peroneus quartus and peroneus digiti quinti. A systematic review and meta-analysis. Surg. Radiol. Anat., 37(6):617-27, 2015.

Ziai, P.; Benca, E.; von Skrbensky, G.; Graf, A.; Wenzel, F.; Basad, E.; Windhager, R. \& Buchhorn, T. The role of the peroneal tendons in passive stabilisation of the ankle joint: an in vitro study. Knee Surg. Sports Traumatol. Arthrosc., 21(6):1404-8, 2013.

\author{
Corresponding author: \\ Benjamin WC Rosser, MSc, PhD \\ Professor Emeritus \\ Department of Anatomy, Physiology and Pharmacology \\ University of Saskatchewan \\ Saskatoon \\ Saskatchewan, S7N 5E5 \\ CANADA
}

Email: Ben.Rosser@usask.ca

Received: 05-11-2018

Accepted: 07-01-2019 